\title{
Papers
}

\section{Association between psychological symptoms in adults and growth in early life: longitudinal follow up study}

\author{
Y B Cheung, K S Khoo, J Karlberg, D Machin
}

\begin{abstract}
Objectives To test the hypothesis that birth weight for gestational age and weight gain in early childhood have a long term association with psychological distress in adults.

Design Longitudinal study of 1958 birth cohort

followed to age 42 years.

Setting Population based birth cohort study.

Participants 9731 cohort members with valid perinatal, postnatal, and adult data.

Main outcome measures Malaise inventory scores measured at ages 23, 33, and 42 years. Generalised estimating equations approach used to analyse repeated measures.

Results Psychological distress score was inversely related to birthweight $\mathrm{z}$ score and weight gain from birth to the age of 7 years. A unit increase in birthweight $\mathrm{z}$ score or childhood weight gain was associated with a mean reduction in psychological distress score of $0.10(95 \%$ confidence interval 0.05 to 0.15 ) and 0.06 (0.02 to 0.10), respectively. Birth weight and weight gain were also inversely related to the odds of having a high level of psychological distress, with odds ratios being 0.90 (0.85 to 0.95 ) and 0.93 (0.89 to 0.98$)$, respectively.

Conclusions Psychological health in adults is related to fetal growth and growth in early childhood.
\end{abstract}

\section{Introduction}

Although numerous studies have shown that fetal and postnatal growth can affect psychological and developmental outcomes in children, it is uncertain whether the influence persists into adulthood. A study of Swedish conscripts showed an inverse relation between birth weight and susceptibility to stress at age $18 .{ }^{1}$ A study of British people born in 1970 showed that birth weight for gestational age is associated with the psychological but not somatic score of the malaise inventory at age 26 years..$^{2}$ In contrast, one study found no association between fetal growth retardation and psychological outcomes in adolescents ${ }^{3}$; another found no association between birth weight and life satisfaction in young adults. ${ }^{4}$ Several investigators have suggested the relevancy of postnatal growth to hormone concentration, metabolism, and blood pressure. ${ }^{56}$

We tested the hypothesis that small size at birth and slow growth in early childhood are associated with higher levels of psychological distress in adults. We used data from the UK national child development study, which followed a cohort of people born in 1958 from birth to age 42 .

\section{Methods}

\section{Participants}

The national child development study (NCDS) is a cohort study of about 17000 people born in England, Wales, and Scotland in one week in March 1958. Data were collected at birth and then at ages $7,11,16,23,33$, and 42 years from medical records, clinical examinations, and face to face as well as self administered interviews. The samples have been shown to be representative of the national population in a similar age range. Details of the cohort study have been reported elsewhere. ${ }^{78}$

Data collected at birth included birth weight; gestational age in weeks determined by last menstrual period; mother's parity, smoking habit during pregnancy, and marital status; and father's social class defined according to the registrar general's classification. Data collected at age 7 years included body weight and housing tenure. The categorisations of the variables are shown in table 1 .

At ages 23, 33, and 42 participants filled in a questionnaire for the malaise inventory. The inventory was developed by Rutter et al, ${ }^{9}$ based on the Cornell medical index. It consists of a 15 item subscale of psychological symptoms and an eight item subscale of somatic symptoms. ${ }^{10}{ }^{11}$ There is a nine item variant of the somatic symptom scale, but the cohort study suggests the eight item version is used (NCDS user manual). A total of at least eight (psychological plus somatic) symptoms indicates a high risk of psychiatric morbidity.

\section{Current study}

The present study was approved by the ethics committee, National Cancer Centre Singapore.

We proportionally assigned the cut-off point of eight symptoms to the psychological and somatic subscales to indicate the high level of distress in each-that is, at least five psychological symptoms and at least three somatic symptoms. To quantify intrauterine growth retardation we standardised birth weight for gestational age separately for each sex, giving a birth weight SD score or z score. ${ }^{12}$ The procedure involves a

\author{
Division of Clinical \\ Trials and \\ Epidemiological \\ Sciences, National \\ Cancer Centre, \\ Singapore 169610 \\ Y B Cheung \\ biostatistician \\ Department of \\ Medical Oncology, \\ National Cancer \\ Centre, Singapore \\ K S Khoo \\ head \\ Clinical Trials \\ Centre, University \\ of Hong Kong, \\ Hong Kong, China \\ J Karlberg \\ director \\ Clinical Trials \\ Research Unit, \\ University of \\ Sheffield, Sheffield \\ S5 7AU \\ D Machin \\ professor \\ Correspondence to: \\ Y B Cheung \\ ctecyb@nccs.com.sg
}

bmj.com 2002;325:749 
Box-Cox transformation towards a normal distribution and then standardisation of the transformed values within each gestational age. ${ }^{12}{ }^{13}$ A unit increase in birthweight $\mathrm{z}$ score is an increase of $1 \mathrm{SD}$ of birth weight for gestational age. Body size measured at age 7 formed the basis of the childhood growth variable. The data collection at age 7 took about one year to complete so the age (in months) at body size measurement was variable. Weight at this measurement was standardised similarly for age and sex. Weight gain in childhood was measured as the difference in weight $\mathrm{z}$ scores at 7 years and at birth. Cohort members with missing growth data at birth or 7 years were not included in the main analyses.

\section{Analysis}

We used a logistic regression model to examine if growth data were related to the four socioeconomic and maternal variables measured at birth. We also used $t$ tests to compare the malaise inventory subscale scores between members included and excluded due to missing growth data. We used analysis of variance to compare the rates of fetal and childhood growth of cohort members by levels of participation 23, 33, and 42 years.

For the main analyses we used the generalised estimating equations approach to analyse psychological and somatic scores at age 23, 33, and 42 in relation to birthweight $\mathrm{z}$ score and weight gain, with adjustment for covariates. ${ }^{14}{ }^{15}$ We used an exchangeable correlation structure to adjust for the correlation between repeated measurements. One set of models estimated the difference in mean score (linear regression) and one estimated the odds ratio for a high level of distress (logistic regression). We first fitted a model with birthweight $\mathrm{z}$ score and all covariates except weight gain as explanatory variables (model I). In a second model we added weight gain (model II). A comparison of the difference in regression coefficients shows whether the influence of birthweight $\mathrm{z}$ score is mediated by weight gain in childhood. ${ }^{16}$ The analyses were performed with Stata (release 6.0; StataCorp, College Station, TX). To examine the importance of the growth variables in relation to others we took plus or minus $1.28 \mathrm{z}$ score as an indication of high (about 90th centile) and low (10th centile) growth rates and multiplied the coefficients in the regression models by 2.56 .

\section{Results}

Characteristics of non-participants

After we excluded stillbirths, infant deaths, and twin births we had complete information at birth and at 7 years on 11115 (67\%) cohort members. Of these, 9731 $(88 \%)$ participated in at least one of the follow up assessments at ages 23,33 , or 42 . Overall $59 \%$ of the eligible cohort members were involved in the present analysis.

Most (94\%) of the cases with missing data at birth or 7 years had incomplete information on birthweight $\mathrm{z}$ score (due to missing gestational age or birthweight data) or weight at 7 years. In a multivariable logistic regression that estimated the odds of having missing anthropometric data at birth or 7 years, all four dichotomous variables included in the model were significant: cohort members whose mothers smoked dur-
Table 1 Descriptive summary of explanatory variables measured at birth and 7 years. Figures are mean (SD) or percentage distribution

\begin{tabular}{|c|c|c|}
\hline Variables & Men $(n=4925)$ & Women $(n=4806)$ \\
\hline Gestational age (weeks) & $39.7(1.7)$ & $39.8(1.7)$ \\
\hline Birth weight $(\mathrm{g})$ & $3417(521)$ & $3273(504)$ \\
\hline Birthweight z score & $0.02(1.00)$ & $0.01(1.00)$ \\
\hline \multicolumn{3}{|l|}{ Father's social class: } \\
\hline I & 4.7 & 4.4 \\
\hline II & 13.4 & 13.6 \\
\hline III & 59.9 & 59.5 \\
\hline IV & 11.3 & 11.8 \\
\hline V & 8.7 & 8.3 \\
\hline Others & 2.0 & 2.4 \\
\hline \multicolumn{3}{|l|}{ Mother's marital status: } \\
\hline Married & 97.4 & 96.8 \\
\hline Unmarried & 2.6 & 3.2 \\
\hline \multicolumn{3}{|l|}{ Parity: } \\
\hline 1 & 36.2 & 36.9 \\
\hline $2-3$ & 48.1 & 47.4 \\
\hline$\geqslant 4$ & 15.7 & 15.7 \\
\hline \multicolumn{3}{|l|}{ Maternal smoking: } \\
\hline Non-smoker & 60.5 & 58.7 \\
\hline Not during pregnancy & 6.3 & 8.2 \\
\hline$<5$ cigarettes/day & 7.5 & 7.7 \\
\hline 5-14 cigarettes/day & 21.3 & 21.1 \\
\hline$\geqslant 15$ cigarettes/day & 4.5 & 4.3 \\
\hline \multicolumn{3}{|l|}{ Housing tenure at 7 years: } \\
\hline Owner occupier & 43.7 & 43.5 \\
\hline Council tenant & 39.0 & 39.6 \\
\hline Private tenant & 11.4 & 11.2 \\
\hline Others & 5.9 & 5.7 \\
\hline Weight gain (change in z score) & $0.01(1.17)$ & $0.01(1.20)$ \\
\hline
\end{tabular}

ing pregnancy (odds ratio 1.07; 95\% confidence interval 1.00 to 1.14 ), whose mothers were unmarried (1.87; 1.58 to 2.20$)$, whose father's social class was IV or $\mathrm{V}$ or others $(1.22 ; 1.13$ to 1.32$)$, and who had three or more older siblings $(1.19 ; 1.09$ to 1.30$)$ had an increased odds of having missing growth data. Furthermore, among cohort members who at any time completed the malaise inventory, those with missing data at birth or 7 years had higher levels of psychological and somatic distress. For instance, at age 23 the difference in mean in psychological score of was 0.19 (0.09 to 0.27$)$.

\section{Modelling of psychosomatic distress}

The subsequent analyses included only cohort members in the main analysis set-that is, members with valid data at birth and 7 years and who participated in at least one adult follow up. Table 1 gives a summary of the birth, maternal, and socioeconomic variables. Table 2 shows a comparison of the key explanatory variables according to participation in the adult follow up. For both men and women, non-participants and those who took part in one, two, or three follow ups had essentially the same mean birthweight $\mathrm{z}$ score and weight gain. Table 3 shows the number of cohort members and mean (SD) malaise inventory subscale scores, as well as the proportions with high scores, by sex and age. Women had higher psychological and somatic scores at all ages. Somatic subscale scores increased steadily with age. Psychological subscale scores were lower at age 33 than 23, suggesting transition into adulthood (age 23) was a relatively stressful stage. 
Table 4 presents the summary findings of the multiple regression analyses of psychological score. Full details of model II are given in table 5 . In model I a unit increase in birthweight $\mathrm{z}$ score was associated with a reduction of 0.05 (0.01 to 0.09 ) in mean psychological score. The odds ratio for a high level of psychological distress was 0.95 (0.92 to 0.99 ). When we added weight gain to the variables of model I (model II) the reduction in mean psychological score increased to 0.10 (0.05 to 0.14$)$. A higher weight gain was also associated with a lower mean psychological score, the reduction being 0.06 (0.02 to 0.10$)$. The odds ratios were 0.90 (0.85 to 0.95$)$ and 0.93 (0.89 to 0.98 ) for birthweight $\mathrm{z}$ score and weight gain, respectively.

We found no association between somatic distress and birthweight $\mathrm{z}$ score and weight gain (details not shown). All mean differences were close to zero and the odds ratios were close to one.

\section{Comparison of clinical importance}

On the basis of the regression coefficients in table 5, the reduction in mean psychological score between having a high or low fetal growth was $0.10 \times 2.56$ or 0.26 . This reduction is comparable with that between social classes I and IV, between owner occupier and council tenants, and between being a non-smoker and smoking 5-14 cigarettes per day during pregnancy (table 5). Similarly, the possible impact of weight gain in childhood is $-0.06 \times 2.56$ or -0.15 . This is comparable with the difference between social classes I and III or between being a non-smoker and smoking 1-5 cigarettes per day during pregnancy.

\section{Discussion}

This study of the early origins of psychological distress in the 1958 British birth cohort is unique in that the sample size was large, members were followed up to 42 years of age, and growth in childhood was measured. The analyses adjusted for major potential confounders, such as father's social class and maternal smoking. Loss to follow up in a longitudinal study over 40 years is inevitable. However, nearly three fifths of the cohort members were available for the main analyses. This proportion is much higher than in other studies with shorter follow up times. Our analysis showed that participation in adult follow up was unrelated to birthweight $\mathrm{z}$ score and postnatal weight gain among those with valid growth data. Missing growth data tended to correlate with a disadvantaged socioeconomic and maternal health background as well as a higher level of distress in adults. As such, the available data tended to emphasise members with relatively good growth and psychological health status. Therefore the real magnitude of the effect of growth failure may be stronger than that estimated here. ${ }^{17}$ Whether this is indeed the case remains to be verified by further
Table 2 Comparison of mean (SD) birthweight $z$ score and weight gain by level of participation in follow up at ages 23,33 , and 42 years in national child development study

\begin{tabular}{lcccc} 
Participation & No participation & $\begin{array}{c}\text { Partial (1 or 2 } \\
\text { follow ups) }\end{array}$ & $\begin{array}{c}\text { Full (3 follow } \\
\text { ups) }\end{array}$ & P value \\
\hline Men & \multicolumn{5}{c}{} & \\
\hline No & 818 & 2167 & 2758 & \\
\hline Birthweight z score & $0.03(0.99)$ & $0.00(1.01)$ & $0.03(0.99)$ & 0.45 \\
\hline Weight gain (change in z score) & $-0.07(1.23)$ & $0.01(1.17)$ & $0.01(1.16)$ & 0.16 \\
\hline Women & 566 & 1787 & 3019 & \\
\hline No & $0.03(1.00)$ & $-0.03(0.98)$ & $0.03(1.00)$ & 0.18 \\
\hline Birthweight z score & $-0.07(1.23)$ & $0.01(1.21)$ & $0.01(1.20)$ & 0.83 \\
\hline Weight gain (change in z score) & & & &
\end{tabular}

Table 3 Psychological and somatic subscale scores of malaise inventory by sex and age at follow up

\begin{tabular}{|c|c|c|c|c|}
\hline & \multicolumn{2}{|c|}{ Men } & \multicolumn{2}{|c|}{ Women } \\
\hline & $\begin{array}{l}\text { Psychological } \\
\text { score }\end{array}$ & Somatic score & $\begin{array}{l}\text { Psychological } \\
\text { score }\end{array}$ & Somatic score \\
\hline \multicolumn{5}{|l|}{ At age 23 years } \\
\hline$\overline{\text { No }}$ & 4211 & 4212 & 4240 & 4239 \\
\hline Mean (SD) & $1.33(1.77)$ & $0.62(0.99)$ & $2.43(2.45)$ & $0.87(1.14)$ \\
\hline High distress (\%) & 6.3 & 5.9 & 18.3 & 9.4 \\
\hline \multicolumn{5}{|l|}{ At age 33 years } \\
\hline No & 3721 & 3728 & 3809 & 3809 \\
\hline Mean (SD) & $1.20(1.89)$ & $0.73(1.10)$ & $1.85(2.32)$ & $0.86(1.15)$ \\
\hline High distress (\%) & 6.3 & 8.2 & 12.5 & 9.5 \\
\hline \multicolumn{5}{|l|}{ At age 42 years } \\
\hline No & 3780 & 3780 & 3889 & 3889 \\
\hline Mean (SD) & $2.12(2.50)$ & $0.92(1.24)$ & $2.81(2.78)$ & $1.07(1.30)$ \\
\hline High distress (\%) & 15.5 & 10.1 & 22.2 & 12.6 \\
\hline
\end{tabular}

studies. In 1958 gestation was estimated from the date of the last menstrual period, which might make the birthweight z score imprecise. Studies with data from discordant twins will be useful to confirm our findings because they have the same gestational duration.

Our findings are consistent with those from a previous study of people followed to age 26 in that a higher birthweight $\mathrm{z}$ score is associated with a reduction in the psychological, but not the somatic, subscale score of the malaise inventory. ${ }^{2}$ As the psychological subscale is closely related to stress, ${ }^{10} 1118$ the finding is in line with the hypothesis that people with impaired growth in early life will become more susceptible to stress. ${ }^{1}$ It is of interest that the association between one unit increase in birthweight $\mathrm{z}$ score and the reduction in psychological score strengthened from 0.05 to 0.10 when we adjusted for weight gain in childhood. Small size at birth is usually followed by some degree of postnatal catch up. Our results suggest that the impact of a smaller size at birth is partly compensated by a higher weight gain in infancy.

\section{Conclusions}

We conclude that the association of size at birth and psychological distress persists into middle age.

Table 4 Summary of findings in generalised estimating equations multiple linear regression (mean scores) and logistic regression (odds ratios) models of psychological scores measured at three adult ages*

\begin{tabular}{lccccc} 
& \multicolumn{2}{c}{ Difference in mean (95\% confidence interval) } & & \multicolumn{2}{c}{ Odds ratio (95\% confidence interval) } \\
\cline { 2 - 3 } \cline { 5 - 6 } One unit increase in variable & Model I & Model II & & Model I & Model II \\
\hline Birthweight z score & $-0.05(-0.09$ to -0.01$)$ & $-0.10(-0.14$ to -0.05$)$ & & $0.95(0.92$ to 0.99$)$ & $0.90(0.85$ to 0.95$)$ \\
\hline Weight gain (change in z score) & NA & $-0.06(-0.10$ to -0.02$)$ & & NA & $0.93(0.89$ to 0.98$)$ \\
\hline
\end{tabular}

$\mathrm{NA}=$ not applicable

${ }^{*}$ Adjusted for sex, age at follow up, and covariates in table 1. 
Table 5 Details of generalised estimating equations multiple linear regression (mean score) and logistic regression (odds ratio) models of psychological score measured at three adult ages (summary of key findings given in models II of table 4)

\begin{tabular}{|c|c|c|}
\hline Regressor & Difference in mean $(95 \% \mathrm{Cl})$ & Odds ratio $(95 \% \mathrm{CI})$ \\
\hline Birthweight z score & $-0.10(-0.14$ to -0.05$)$ & $0.90(0.85$ to 0.95$)$ \\
\hline Weight gain (change in z score) & $-0.06(-0.10$ to -0.02$)$ & $0.93(0.89$ to 0.98$)$ \\
\hline \multicolumn{3}{|l|}{ Sex: } \\
\hline Male & 0 & 1 \\
\hline Female & $0.82(0.75$ to 0.90$)$ & 2.08 (1.90 to 2.29 ) \\
\hline \multicolumn{3}{|l|}{ Follow up: } \\
\hline At age 23 & 0 & 1 \\
\hline At age 33 & $-0.34(-0.39$ to -0.28$)$ & 0.75 (0.68 to 0.82$)$ \\
\hline At age 42 & $0.61(0.56$ to 0.66$)$ & $1.72(1.58$ to 1.84$)$ \\
\hline Gestational age (weeks) & $-0.00(-0.02$ to 0.02$)$ & $1.00(0.98$ to 1.03$)$ \\
\hline \multicolumn{3}{|l|}{ Father's social class: } \\
\hline 1 & 0 & 1 \\
\hline II & $-0.01(-0.22$ to 0.20$)$ & $0.94(0.71$ to 1.23$)$ \\
\hline III & $0.20(0.01$ to 0.39$)$ & $1.14(0.89$ to 1.47$)$ \\
\hline IV & 0.31 (0.09 to 0.52$)$ & 1.29 (0.98 to 1.70$)$ \\
\hline V & $0.48(0.25$ to 0.71$)$ & 1.48 (1.11 to 1.97$)$ \\
\hline Others & $-0.11(-0.58$ to 0.36$)$ & 0.98 (0.58 to 1.66$)$ \\
\hline \multicolumn{3}{|l|}{ Mother's marital status: } \\
\hline Married & 0 & 1 \\
\hline Unmarried & $0.62(0.24$ to 1.00$)$ & 1.66 (1.13 to 2.44$)$ \\
\hline \multicolumn{3}{|l|}{ Parity: } \\
\hline 1 & 0 & 1 \\
\hline $2-3$ & 0.13 (0.04 to 0.21$)$ & 1.16 (1.04 to 1.29$)$ \\
\hline$\geqslant 4$ & $0.37(0.25$ to 0.50$)$ & 1.39 (1.21 to 1.58$)$ \\
\hline \multicolumn{3}{|l|}{ Maternal smoking: } \\
\hline Non-smoker & 0 & 1 \\
\hline Not during pregnancy & 0.07 (-0.09 to 0.22$)$ & $1.04(0.87$ to 1.25$)$ \\
\hline$<5$ cigarettes/day & $0.13(-0.02$ to 0.28$)$ & $1.15(0.97$ to 1.36$)$ \\
\hline 5-14 cigarettes/day & 0.26 (0.16 to 0.36$)$ & 1.27 (1.13 to 1.42$)$ \\
\hline$\geqslant 15$ cigarettes/day & 0.39 (0.20 to 0.59$)$ & 1.32 (1.07 to 1.63$)$ \\
\hline \multicolumn{3}{|l|}{ Housing tenure at age 7 years: } \\
\hline Owner occupier & 0 & 1 \\
\hline Council tenant & 0.30 (0.21 to 0.39$)$ & 1.35 (1.21 to 1.51$)$ \\
\hline Private tenant & $0.33(0.20$ to 0.47$)$ & $1.36(1.17$ to 1.60$)$ \\
\hline Others & $0.13(-0.04$ to 0.30$)$ & $1.22(0.99$ to 1.49$)$ \\
\hline
\end{tabular}

Previous studies could only demonstrate such a relation up to the age of 18 or 26 years. Secondly, growth rate from birth to the age of 7 years was also associated with the psychological outcome. Thirdly, the potential impact of small size at birth may be partly compensated for by a faster weight gain in early childhood.

We thank the UK Data Archive and the Centre for Longitudinal Studies, London, for providing data from the national child development study.

Contributors: YBC initiated the idea for the study and contributed to the design, analysis, and writing of the paper. KSK and $\mathrm{JK}$ contributed to the design and the interpretation and discussion of findings. DM contributed to the statistical strategy, interpretation of findings, and writing of the article. YBC is the guarantor.

\section{What is already known on this topic}

Psychological outcomes in children are related to fetal growth and postnatal growth

Size at birth is also associated with psychological outcomes in adolescents and young adults

\section{What this study adds}

Both birthweight $\mathrm{z}$ score and weight gain in early childhood are associated with psychological distress at ages 23 to 42

The impact of a smaller size at birth may be compensated for by a higher postnatal weight gain

Funding: YBC and DM were supported by the National Medical Research Council of Singapore.

Competing interests: None declared.

1 Nilsson PM, Nyberg P, Ostergren PO. Increased susceptibility to stress at a psychological assessment of stress tolerance is associated with impaired fetal growth. Int J Epidemiol 2001;30:75-80.

2 Cheung YB. Early origins and adult correlates of psychosomatic distress. Soc Sci Med 2002;55:937-48

3 Lagerstrom M, Bremme K, Eneroth P, Janson CG. Long-term development for girls and boys at age 16-18 as related to birthweight and gestational age. Int J Psychophysiology 1994;17:175-80.

4 Strauss RS. Adult functional outcome of those born small for gestational age. JAMA 2000;283:625-32.

5 Cianfarani S, Germani D, Branca F. Low birthweight and adult insulin resistance: the "catch-up growth" hypothesis. Arch Dis Child Fetal Neonat Ed 1999;81:F71-3.

6 Cheung YB, Low LCK, Osmond C, Barker DJP, Karlberg JPE. Fetal growth and early postnatal growth are related to blood pressure in adults. Hypertension 2000;36:795-800.

7 Ferri E. Life at 33: the fifth follow-up of the National Child Development Study. London: National Children's Bureau, 1993.

8 Power C, Manor O, Fox J. Health and class: the early years. London: Chapman and Hall, 1991.

9 Rutter M, Tizard J, Whitmore K. Education, health and behaviour. London: Longmans, 1970.

10 Grant G, Nolan M, Ellis N. A reappraisal of the malaise inventory. Soc Psychiatry Psychiatr Epidemiol 1990;25:170-8.

11 Rodgers B, Pickles A, Power C, Collishaw S, Maughan B. Validity of the malaise inventory in general population samples. Soc Psychiatry Psychiatr Epidemiol 1999;34:333-41.

12 Niklasson A, Ericson A, Fryer JG, Karlberg J, Lawrence C, Karlberg P. An update of the Swedish reference standards for weight, length and head circumference at birth for given gestational age (1977-1981). Acta Paediatr Scand 1991;80:756-62.

13 Box GEP, Cox DR. An analysis of transformations. J Roy Stat Soc Series B 1964;26:211-43

14 Liang KY, Zeger SL. Longitudinal data analysis using generalized linear models. Biometrika 1986;73:13-22.

15 Fayers PM, Machin D. Quality of life: assessment, analysis and interpretation. Chichester: Wiley, 2000.

16 Lucas A, Fewtrell MS, Cole TJ. Fetal origin of adult disease: the hypothesis revisited. BMJ 1999;319:245-9.

17 Cheung YB. Adjustment for selection bias in cohort studies: an application of a probit model with selectivity to life course epidemiology. J Clin Epidemiol 2001:54:1238-43.

18 Hirst MA, Bradshaw JR. Evaluating the malaise inventory: a comparison of measures of stress. J Psychosom Res 1983;27:193-9.

(Accepted 20 June 2002) 